\title{
A new marker for breast cancer diagnosis, human epididymis protein 4: A preliminary study
}

\author{
UMUT RIZA GÜNDÜZ ${ }^{1}$, MERAL GUNALDI ${ }^{2}$, NILGUN ISIKSACAN ${ }^{3}$, SEYDA GÜNDÜZ $^{4}$, \\ YILDIZ OKUTURLAR ${ }^{5}$ and HAKAN KOCOGLU ${ }^{5}$
}

\author{
${ }^{1}$ Department of General Surgery, Antalya Education and Research Hospital, Antalya 07100; \\ Departments of ${ }^{2}$ Medical Oncology and ${ }^{3}$ Biochemistry, Bakırköy Education and Research Hospital, Istanbul 07100; \\ ${ }^{4}$ Department of Medical Oncology, Antalya Education and Research Hospital, Antalya 07100; ${ }^{5}$ Department \\ of Internal Medicine, Bakırköy Education and Research Hospital, Istanbul 34147, Turkey
}

Received September 22, 2015; Accepted May 9, 2016

DOI: $10.3892 / \mathrm{mco} .2016 .919$

\begin{abstract}
Breast cancer is the most frequently diagnosed cancer type in women. Tumor markers have been widely used for assessing the treatment response and early diagnosis of recurrence. Human epididymis protein 4 (HE4) is expressed in ductal carcinoma of the breast tissue; however, its serum levels and their diagnostic and prognostic potential in breast cancer have not been investigated, which was therefore the aim of the present study. The serum levels of HE4 were determined in 36 breast cancer patients, 11 ovarian cancer patients and 16 healthy volunteers. The association between clinicopathological characteristics of breast cancer and serum HE4 levels was investigated. A significant difference in the median serum levels of HE4 was identified between breast cancer patients, ovarian cancer patients and healthy volunteers $(\mathrm{P}=0.013)$. The cutoff value for the prediction of breast cancer was determined at $>13.24 \mathrm{pmol} / \mathrm{l}$ for HE4, with a sensitivity of $61.11 \%$, specificity of $68.75 \%$, positive predictive value of $81.48 \%$, negative predictive value of $44.0 \%$ and accuracy of $63.46 \%$. Furthermore, a positive correlation between the serum levels of HE4 and cancer antigen 15-3 was determined ( $\mathrm{r}=0.399$, $\mathrm{P}=0.026$ ). To the best of our knowledge, the present study was the first to determine the diagnostic value of serum HE4 for breast cancer. A significant elevation of serum HE4 levels in patients with breast cancer compared with that in healthy controls was identified. HE4 may serve as a novel biomarker for the diagnosis of breast cancer.
\end{abstract}

Correspondence to: Dr Umut Riza Gündüz, Department of General Surgery, Antalya Education and Research Hospital, Varlık Mahallesi, Kazim Karabekir Caddesi, Antalya 07100, Turkey

E-mail: utg1@yahoo.com

Key words: human epididymis protein 4, cancer antigen 15-3, diagnostic marker, breast cancer

\section{Introduction}

Breast cancer is the most commonly diagnosed cancer in women. According to the Surveillance, Epidemiology and End Results database, it is the third most common cause of cancer-associated mortality in women (1). Although certain preventive approaches or early screening programs may reduce the risk for breast cancer, the majority of cases cannot be eliminated, particularly in developing countries where breast cancer is diagnosed in late stages. Early detection is therefore vital to improve the outcome and survival and is the cornerstone for the management of breast cancer patients. Tumor markers have been widely used for assessment of treatment responses, early diagnosis of recurrence and prognosis. In breast cancer, the most generally used serum tumor marker is cancer antigen 15-3 (CA 15-3); however, its sensitivity and specificity are inadequate $(2,3)$. Numerous serum markers have been studied, however, none have been implemented for routine clinical practice (4).

Human epididymal protein 4 (HE4) is a secretory protein initially identified in epithelial cells of the human epididymis (5). Expression of HE4 has been demonstrated in numerous types of normal human tissues, particularly in the epithelium of the respiratory and genitourinary tracts of men and women, and increased HE4 expression has been demonstrated in a range of malignant neoplasms, particularly those of gynecological, pulmonary and gastrointestinal origin (6-9).

As recently reported, HE4 is also expressed in ductal carcinoma of the breast tissue (6); however, the serum expression levels and their diagnostic and prognostic potential in breast cancer remain to be elucidated. The aim of the present study was to examine the association between the serum expression levels of HE4 and the clinicopathological variables, and to assess the potential use of circulating HE4 for the diagnosis of breast cancer.

\section{Materials and methods}

The present study was approved by the ethics committee of Bakırköy Education and Research Hospital (Istanbul, Turkey), and written informed consent was provided prior to the 
Table I. Comparison of HE4 levels in patients with breast cancer and the healthy controls.

HE4 level, pmol/1

\begin{tabular}{lcccr}
\cline { 3 - 4 } Group & Total, $\mathrm{n}$ & Mean \pm standard deviation & Min-max (median) & P-value \\
\hline Control & 16 & $11.94 \pm 2.19$ & $8.91-16.52(11.52)$ & $0.013^{\mathrm{a}}$ \\
Breast cancer & 36 & $26.83 \pm 26.19$ & $10.05-107.37(14.63)$ & $0.006^{\mathrm{b}}$ \\
Ovarian cancer & 11 & $21.12 \pm 14.05$ & $10.20-50.05(16.47)$ & $0.017^{\mathrm{b}}$ \\
\hline
\end{tabular}

Significant difference when comparing with a all groups or ${ }^{\mathrm{b}}$ control group. HE4, human epididimis protein 4.

assessment. This prospective clinical trial was performed at the Department of Medical Oncology (Bakırköy Education and Research Hospital (Istanbul, Turkey). The patient cohort consisted of 63 women: 36 with breast cancer, 11 with ovarian cancer, and 16 age- and body mass index-matched healthy volunteers. Breast and ovarian cancer patients who had undergone chemotherapy or radiation therapy following surgery and patients with other types of cancer were excluded.

The characteristics of the breast cancer patients with regards to age, menopausal status, histopathological type, tumor size, tumor lymph node metastasis and tumor grade, as well as estrogen receptor (ER), progesterone receptor (PR), human epidermal growth factor-2 (HER2) status, lymphovascular invasion, perineural invasion status and stage were collected for data analysis.

The pathological tumor stage was defined according to the seventh edition of the tumor-nodes-metastasis Classification of Malignant Tumours of the Union for International Cancer Control (10). Tumor differentiation was defined according to the World Health Organization Classification of Tumours of the Breast, fourth edition (11). Tumors were classified as $>2 \mathrm{~cm}, 2-5 \mathrm{~cm}$ or $>5 \mathrm{~cm}$; tumor size and lymph node metastasis status were evaluated separately. ER, PR and HER2 data were obtained from the pathology records of the patients.

Blood sample collection. Venous blood samples were collected in tubes from the antecubital vein following an overnight fast. The tubes were centrifuged at 2,000 $\mathrm{x}$ g for $10 \mathrm{~min}$ to separate the plasma and the serum. The plasma and the serum samples were kept at $-80^{\circ} \mathrm{C}$ until analysis of the HE4 levels.

Measurement of HE4. HE4 was measured using an enzyme-linked immunosorbent assay based on the biotin double antibody sandwich technology (One Step RT-PCR kit) according to the manufacturer's protocol (Shanghai Yehua Biological Technology, Shanghai, China). The range of reference values was $0.5-150 \mathrm{pmol} / 1$.

Other variables. CA 125, carcinoembryonic antigen (CEA) and CA 15-3 were measured in the serum samples. The complete blood count (CBC) was determined from whole blood samples containing ethylenediamine tetraacetate.

The CBC was determined in a Coulter LH 750 autoanalyzer (Beckman Coulter, Brea, CA, USA). CA 125, CEA and CA 15-3 were determined using a Beckman Coulter AU5800 chemistry autoanalyzer and DXI 800 systems using commercial kits (all from Beckman Coulter) with a one-step dual monoclonal antibody assay method. Ranges of reference values were as follows: CA 125, 0-11.1 U/ml; CA 15-3, 0-31.3 U/ml; and CEA, 0-3.0 ng/ml.

Statistical analysis. Statistical analysis was performed using the Number Cruncher Statistical System (NCSS) 2007 and Power Analysis and Sample Size 2008 statistical software (NCSS, LLC, Kaysville, Utah, USA). Descriptive statistical methods were used for the evaluation of study variables. For comparison of variables with a normal distribution, the Kruskal Wallis test was used, and the Mann-Whitney U test was used for comparison of variables with a non-Gaussian distribution. Spearman's rho correlation analysis was used to assess the association between HE4 and CA 15-3, which did not show conformity with a normal distribution. Receiver operating characteristic (ROC) analysis was used for the determination of the aptness of HE4 for clinical differentiation between the patient and the control groups. When the area under the curve (AUC) was found to be significant, the cutoff values were determined and sensitivity and specificity for that particular cutoff point were calculated. The 95\% confidence interval (CI) was evaluated for the results. $\mathrm{P}<0.05$ was considered to indicate a statistically significant difference.

\section{Results}

Serum levels of HE4. The serum levels of HE4 were determined in 36 breast cancer patients, 11 ovarian cancer patients and 16 healthy volunteers. The association between the clinicopathological characteristics of breast cancer and serum levels of HE4 was investigated.

Associations bewteen HE4 and clinicopathological characteristics. No significant differences were observed between the mean age of the breast cancer patients, ovarian cancer patients and healthy volunteers $(61.39 \pm 12.99,60.0 \pm 15.57$ and $58.19 \pm 10.88$ years, respectively, $\mathrm{P}=0.739$ ).

There was a significant difference in the median serum levels of HE4 in breast cancer patients, ovarian cancer patients and healthy volunteers $(14.63,16.47$ and $11.52 \mathrm{pmol} / \mathrm{l}$, respectively; $\mathrm{P}=0.013$ ). No significant differences between the breast cancer and ovarian cancer patient groups was observed, the median serum levels of HE4 in these groups were significantly higher than those in the healthy volunteer group $(\mathrm{P}=0.006$ and $\mathrm{P}=0.017$, respectively) (Table I).

No significant associations between the serum levels of HE4 with comorbidity, menopausal status, hormone receptor status, 
Table II. Comparison of clinicopathological features and the serum HE4 levels in breast cancer patients.

\begin{tabular}{|c|c|c|c|c|}
\hline \multirow[b]{2}{*}{ Clinicopathological feature } & \multirow[b]{2}{*}{ Total, \% } & \multicolumn{2}{|c|}{ HE4 level, pmol/1 } & \multirow[b]{2}{*}{ P-value } \\
\hline & & Mean \pm standard deviation & Median & \\
\hline \multicolumn{5}{|l|}{ Menopausal status } \\
\hline Post & 72.2 & $24.25 \pm 26.12$ & 12.54 & 0.241 \\
\hline Pre & 27.8 & $27.82 \pm 26.67$ & 16.02 & \\
\hline \multicolumn{5}{|l|}{ Comorbidity } \\
\hline$(-)$ & 58.3 & $31.56 \pm 26.44$ & 16.02 & 0.849 \\
\hline$(+)$ & 41.7 & $23.45 \pm 26.12$ & 13.88 & \\
\hline \multicolumn{5}{|l|}{ Estrogen receptor } \\
\hline$(-)$ & 65.7 & $31.15 \pm 28.89$ & 19.20 & 0.482 \\
\hline$(+)$ & & $25.28 \pm 25.48$ & 13.79 & \\
\hline \multicolumn{5}{|l|}{ Progesterone receptor } \\
\hline$(-)$ & 57.1 & $27.05 \pm 21.83$ & 18.16 & 0.521 \\
\hline$(+)$ & & $27.48 \pm 29.97$ & 13.56 & \\
\hline \multicolumn{5}{|l|}{ Triple negative } \\
\hline$(-)$ & 25.7 & $28.25 \pm 29.07$ & 13.83 & 0.697 \\
\hline$(+)$ & & $24.54 \pm 17.75$ & 18.16 & \\
\hline \multicolumn{5}{|l|}{ HER2 } \\
\hline$(-)$ & 20.0 & $26.17 \pm 26.04$ & 15.58 & 0.672 \\
\hline$(+)$ & & $31.79 \pm 29.58$ & 12.14 & \\
\hline \multicolumn{5}{|l|}{ Lymphovascular invasion } \\
\hline$(-)$ & 40.0 & $26.55 \pm 23.27$ & 16.02 & 0.538 \\
\hline$(+)$ & & $28.41 \pm 31.48$ & 12.62 & \\
\hline \multicolumn{5}{|l|}{ Perineural invasion } \\
\hline$(-)$ & 37.5 & $26.98 \pm 25.18$ & 14.63 & 0.833 \\
\hline$(+)$ & & $31.46 \pm 31.38$ & 16.80 & \\
\hline \multicolumn{5}{|l|}{ Metastasis } \\
\hline$(-)$ & 13.9 & $25.20 \pm 23.88$ & 13.79 & 0.191 \\
\hline$(+)$ & & $36.93 \pm 39.74$ & 20.25 & \\
\hline \multicolumn{5}{|l|}{ Histopathological type } \\
\hline Invasive ductal carcinoma & 75.0 & $28.20 \pm 24.59$ & 16.27 & 0.113 \\
\hline Other & & $23.92 \pm 33.78$ & 11.84 & \\
\hline \multicolumn{5}{|l|}{ Grade } \\
\hline 1 & 3.2 & 13.88 & 13.88 & 0.777 \\
\hline 2 & 64.5 & $29.52 \pm 30.05$ & 14.58 & \\
\hline 3 & 32.3 & $25.89 \pm 22.10$ & 19.21 & \\
\hline \multicolumn{5}{|l|}{ Depth of invasion } \\
\hline 1 & 13.9 & $22.41 \pm 15.76$ & 15.38 & 0.655 \\
\hline 2 & 61.1 & $26.49 \pm 26.16$ & 13.83 & \\
\hline 3 & 8.3 & $13.62 \pm 3.85$ & 12.79 & \\
\hline 4 & 16.7 & $38.38 \pm 37.93$ & 21.00 & \\
\hline \multicolumn{5}{|l|}{ Lymph node metastasis } \\
\hline 0 & 61.1 & $27.30 \pm 25.04$ & 15.90 & 0.197 \\
\hline 1 & 11.1 & $11.51 \pm 1.26$ & 11.60 & \\
\hline 2 & 19.4 & $26.15 \pm 22.62$ & 12.14 & \\
\hline 3 & 8.3 & $45.36 \pm 53.81$ & 17.82 & \\
\hline \multicolumn{5}{|l|}{ Stage } \\
\hline 1 & 11.1 & $25.50 \pm 16.35$ & 19.86 & 0.176 \\
\hline 2 & 52.8 & $26.14 \pm 26.63$ & 13.88 & \\
\hline 3 & 22.2 & $22.82 \pm 22.27$ & 10.90 & \\
\hline 4 & 13.9 & $36.93 \pm 39.74$ & 20.25 & \\
\hline
\end{tabular}

HE4, human epididimis protein 4; HER2, human epidermal growth factor-2. 
Table III. Association between HE4 levels and blood parameters or cancer markers in breast cancer.

\begin{tabular}{|c|c|c|c|c|}
\hline \multirow[b]{2}{*}{ Variable } & \multirow[b]{2}{*}{ Total, \% } & \multicolumn{2}{|c|}{ HE4 level, pmol/l } & \multirow[b]{2}{*}{ P-value } \\
\hline & & Mean \pm standard deviation & Median & \\
\hline \multicolumn{5}{|c|}{ Leukocytosis } \\
\hline$(-)$ & 20.0 & $26.57 \pm 24.76$ & 13.83 & 0.856 \\
\hline$(+)$ & & $28.60 \pm 35.14$ & 15.78 & \\
\hline \multicolumn{5}{|l|}{ Anemia } \\
\hline$(-)$ & 38.2 & $26.77 \pm 27.20$ & 13.24 & 0.462 \\
\hline$(+)$ & & $27.29 \pm 27.68$ & 16.27 & \\
\hline \multicolumn{5}{|c|}{ Thrombocytosis } \\
\hline$(-)$ & 20.0 & $30.34 \pm 28.74$ & 14.63 & 0.095 \\
\hline$(+)$ & & $13.51 \pm 3.97$ & 11.55 & \\
\hline \multicolumn{5}{|c|}{ CEA (ref: 0-3.0 ng/ml) } \\
\hline Normal & 24.0 & $26.79 \pm 25.97$ & 13.88 & 0.274 \\
\hline High & & $22.09 \pm 25.45$ & 10.90 & \\
\hline \multicolumn{5}{|c|}{ CA 125 (ref: 0-11.1 U/ml) } \\
\hline Normal & 7.7 & $26.66 \pm 25.64$ & 13.83 & 0.501 \\
\hline High & & $13.96 \pm 5.45$ & 13.96 & \\
\hline \multicolumn{5}{|c|}{ CA 15-3 (ref: 0-31.3 U/ml) } \\
\hline Normal & 19.4 & $22.17 \pm 18.14$ & 13.88 & 0.031 \\
\hline High & & $56.97 \pm 42.93$ & 56.04 & \\
\hline
\end{tabular}

CEA, carcinoembryogenic antigen; CA, cancer antigen.

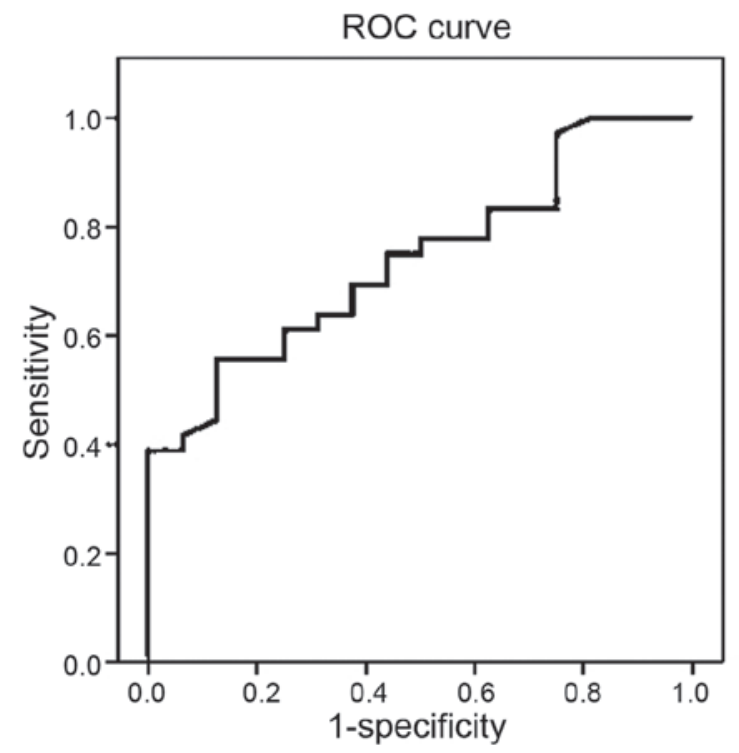

Figure 1. ROC curve for serum HE4 levels in the diagnosis of breast cancer. The area under the curve for HE4 is 0.740 with $\mathrm{P}=0.006$. ROC, receiver operating characteristic; HE4, human epididymis protein 4.

HER-2 status, lymphovascular invasion, perineural invasion or metastases were identified in breast cancer patients $(\mathrm{P} \geq 0.05)$. In addition, no differences between the median serum levels of HE4 in breast cancer patients and the tumor grade, histopathological subgroup, lymph node metastases and stage $(\mathrm{P} \geq 0.05)$ (Table II).

Breast cancer patients with high serum levels of CA 15-3 had a significantly higher serum level of HE4

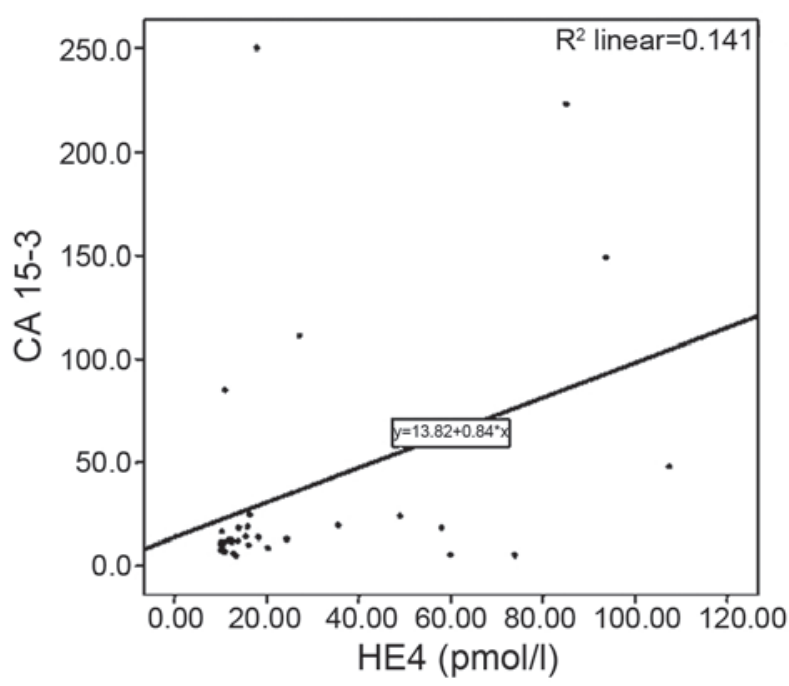

Figure 2. Correlation analysis between serum levels of HE4 and CA 15-3 in breast cancer patients $(\mathrm{r}=0.399 ; \mathrm{P}=0.026)$. HE4, human epididymis protein 4; CA, cancer antigen.

compared to those with low CA 15-3 levels $(56.97 \pm 42.93$ vs. $22.17 \pm 18.14 \mathrm{pmol} / 1$, respectively; $\mathrm{P}=0.031)$. However, no significant difference was observed between the median serum level of HE4 in patient groups with low and high serum levels of CEA and CA 125. Furthermore, no association between the serum levels of HE4 and leukocytosis, anemia and thrombocytosis was identified $(\mathrm{P} \geq 0.05)$ (Table III).

The cutoff value of HE4 levels for predicting breast cancer was determined by ROC analysis. The cutoff value for the 
prediction of breast cancer was determined at $>13.24 \mathrm{pmol} / 1$ for HE4 with a sensitivity of $61.11 \%$, specificity of $68.75 \%$, positive predictive value of $81.48 \%$, negative predictive value of $44.0 \%$ and accuracy of $63.46 \%$ [AUC, 0.740 (95\% CI, 0.604-0.875), $\mathrm{P}=0.006$ ] (Fig. 1).

Furthermore, a positive correlation was determined between the serum levels of HE4 and CA 15-3 in breast cancer patients ( $\mathrm{r}=0.399 ; \mathrm{P}=0.026)$ (Fig. 2).

\section{Discussion}

To the best of our knowledge, the present study was the first to determine the diagnostic value of serum HE4 for breast cancer patients. Breast cancer is a heterogeneous group of diseases that differs in their pathological characteristics and clinical presentation. The risk of recurrence and prognosis are affected by the stage at diagnosis and biological features of the tumor. The main challenge regarding biomarkers for breast cancer diagnosis is to improve the accuracy for the detection of the malignancy at the earliest possible stage. Numerous serum markers, including BR 27.29 (CA 27.29), mucin-like carcinoma-associated antigen, CA 549 and CEA, have been investigated; however, none of these markers have reached the sensitivity and specificity required for standard clinical practice (4).

According to American Society of Clinical Oncology guidelines, CA 15-3 concentrations are increased in 10\% of patients with stage I of the disease, $20 \%$ in stage II, $40 \%$ in stage III and $75 \%$ in stage IV. Furthermore, CA 15-3 concentrations 5- to 10-fold above the upper limit of the reference interval may alert a physician to the presence of metastatic disease. However, a low concentration does not exclude metastasis (12). In addition, Molina et al (13) showed that the sensitivity of CA 15-3 was $16-18 \%$ in patients with locoregional disease and $61-70 \%$ in those with advanced disease. Due to its lack of specificity and sensitivity with regards to breast cancer, CA 15-3 is not recommended for either screening or early diagnosis.

HE4, also known as whey acidic four-disulfide core domain protein 2 (WFDC2), is a protein encoded by the WFDC2 gene. Due to similarities of HE4 with other whey acidic protein family members, it has been implied that the protein may function as an anti-proteinase (6,7). Furthermore, a recent study by LeBleu et al (14) reported that HE4 functions as a serine protease inhibitor, decreasing the activity of serine proteases Prss35 and Prss23, which degrade type I collagen that accumulates in kidney fibrosis.

The potential use of HE4 as a tumor marker has been supported by an increasing number of studies demonstrating an upregulation of HE4 in a range of malignant neoplasms, particularly of gynecological, pulmonary and gastrointestinal origin (6-9). The serological detection of HE4 has been shown to have increased sensitivity and specificity in the detection of ovarian cancer compared with CA 125, which is the current gold standard serum biomarker for ovarian carcinoma $(7,15,16)$. As aforementioned, previous studies have demonstrated the diagnostic and prognostic potential of the serum levels of HE4 in several other cancer types, including those of gynecological and gastrointestinal origin $(7,9,15,16)$. While all these studies indicated that the cutoff point for HE4 is $70-150 \mathrm{pmol} / \mathrm{l}$ for ovarian cancer, the prediction of HE4 for breast cancer was determined as $>13.24 \mathrm{pmol} / \mathrm{l}$ in the present study.
Galgano et al (6) reported the mRNA and protein expression of HE4 in normal and malignant tissues. Positive HE4 immunoreactivity was present in ovarian cancer, as well as other types of cancer, including lung, endometrial, breast and gastrointestinal cancer and mesothelioma (6). The highest expression levels were found in ovarian serous cancer, and significant positive staining was identified in breast carcinoma tissues. However, malignant breast tissue showed variable expression (6). In addition, Kamei et al (17) found that the increased expression of HE4 in breast cancer tissues correlated with lymph node invasion and was a possible predictive factor of breast cancer recurrence. The five-year disease-free survival in the HE4-positive group (58.6\%) was significantly worse than that in the negative group (85.6\%). These findings indicated that HE4 is significant in association with breast cancer. However, to the best of our knowledge, the serum levels of HE4 in breast cancer patients, and their diagnostic and prognostic potential have not been investigated. In the present study, the serum levels of HE4 in patients diagnosed with breast and ovarian cancer were assessed prior to chemotherapy and compared with those in healthy individuals. The serum levels of HE4 were significantly increased in patients with breast and ovarian cancer compared with those in healthy controls. However, multivariate analysis did not show any significant positive correlation of HE4 serum levels with histological grade, lymph node involvement and clinical stage in breast cancer patients. Of note, the serum levels of HE4 were positively correlated with the serum levels of CA 15-3 in patients with breast cancer. The sensitivity of serum HE4 was $61.11 \%$ and the specificity was $68.75 \%$ for distinguishing breast cancer patients from healthy controls. These findings indicate that HE4 may be used as a predictive marker for breast carcinoma.

The present study has certain limitations, the most evident of which was the small sample size. In future studies, it may be appropriate to compare the serum levels of HE4 with those in tumor tissue since it would be of interest to ascertain the distribution of the HE4 protein and/or mRNA in normal tissue, ductal carcinoma in situ and invasive tumors, i.e. by immunohistochemistry and polymerase chain reaction analysis. The observations of the present study should be confirmed by future studies using a larger cohort and additional tissue analyses.

In conclusion, the present study found a significant elevation of serum HE4 levels in patients with breast cancer compared with those in healthy controls. The preliminary results indicate that HE4 may serve as a novel biomarker for breast cancer. However, large-scale clinical studies are required to further determine the predictive value of this biomarker.

\section{References}

1. Howlader N, Noone AM, Krapcho M, et al: SEER Cancer Statistics Review, 1975-2011, National Cancer Institute. Bethesda, MD, based on November 2015 SEER data submission. http://seer.cancer.gov/archive/csr/1975_2011/. Accessed December 17, 2014.

2. Geng B, Liang MM, Ye XB and Zhao WY: Association of CA 15-3 and CEA with clinicopathological parameters in patients with metastatic breast cancer. Mol Clin Oncol 3: 232-236, 2015.

3. Ideo H, Hinoda Y, Sakai K, Hoshi I, Yamamoto S, Oka M, Maeda K, Maeda N, Hazama S, Amano J and Yamashita K: Expression of mucin 1 possessing a 3'-sulfated core1 in recurrent and metastatic breast cancer. Int J Cancer 137: 1652-1660, 2015.

4. Donepudi MS, Kondapalli K, Amos SJ and Venkanteshan P: Breast cancer statistics and markers. J Cancer Res Ther 10: 506-511, 2014. 
5. Kirchhoff C, Habben I, Ivell R and Krull N: A major human epididymis-specific cDNA encodes a protein with sequence homology to extracellular proteinase inhibitors. Biol Reprod 45: 350-357, 1991.

6. Galgano MT, Hampton GM and Frierson HF Jr: Comprehensive analysis of HE4 expression in normal and malignant human tissues. Mod Pathol 19: 847-853, 2006.

7. Hellström I, Raycraft J, Hayden-Ledbetter M, et al: The HE4 (WFDC2) protein is a biomarker for ovarian carcinoma. Cancer Res 63: 3695-3700, 2003.

8. Bingle L, Cross SS, High AS, et al: WFDC2 (HE4): A potential role in the innate immunity of the oral cavity and respiratory tract and the development of adenocarcinomas of the lung. Respir Res 7: 61, 2006.

9. O'Neal RL, Nam KT, LaFleur BJ, et al: Human epididymis protein 4 is up-regulated in gastric and pancreatic adenocarcinomas. Hum Pathol 44: 734-742, 2013.

10. The TNM Classification of Malignant Tumours of the Union for International Cancer Control. Sobin LH, Gospodarowicz MK and Wittekin C (eds). 7th edition. Wiley-Blackwell, Hoboken, 2009.

11. World Health Organization (WHO) Classification of Tumours of the Breast. Lakhani, SR, Ellis IO, Schnitt SJ, Tan PH and van de Vijver MJ (eds.). 4th edition. WHO Press, 2012.

12. Clinical practice guidelines for the use of tumor markers in breast and colorectal cancer. Adopted on May 17, 1996 by the American Society of Clinical Oncology. J Clin Oncol 14: 2843-2877, 1996.
13. Molina R, Jo J, Filella X, Zanon G, Pahisa J, Mu noz M, Farrus B, Latre ML, Escriche C, Estape J, et al: c-erbB-2 oncoprotein, CEA, and CA 15.3 in patients with breast cancer: Prognostic value. Breast Cancer Res Treat 51: 109-119, 1998.

14. LeBleu VS, Teng Y, O'Connell JT, Charytan D, Müller GA, Müller CA, Sugimoto $H$ and Kalluri R: Identification of human epididymis protein-4 as a fibroblast-derived mediator of fibrosis. Nat Med 19: 227-231, 2013.

15. Ferraro S, Braga F, Lanzoni M, Boracchi P, Biganzoli EM and Panteghini M: Serum human epididymis protein 4 vs carbohydrate antigen 125 for ovarian cancer diagnosis: A systematic review. J Clin Pathol 66: 273-281, 2013.

16. Zhen S, Bian LH, Chang LL and Gao X: Comparison of serum human epididymis protein 4 and carbohydrate antigen 125 as markers in ovarian cancer: A meta-analysis. Mol Clin Oncol 2: 559-566, 2014.

17. Kamei M, Yamashita S, Tokuishi K, Hashioto T, Moroga T, Suehiro S, Ono K, Miyawaki M, Takeno S, Yamamoto S and Kawahara K: HE4 expression can be associated with lymph node metastases and disease-free survival in breast cancer. Anticancer Res 30: 4779-4783, 2010. 